\title{
ABO blood groups and Helicobacter pylori cagA infection: evidence of an association
}

\section{Mattos DE (1), Cintra JR (2), Brandão de Mattos CC (3), Nakashima F (4), Silva RCMA (5), Moreira HW (1), de Mattos LC $(2,3)$}

(1) Clinical Analysis Department, School of Pharmaceutical Sciences, São Paulo State University, UNESP, Araraquara, São Paulo State, Brazil; (2) Regional Blood Center of São José do Rio Preto, Regional Medical School Foundation, FUNFARME, São José do Rio Preto, São Paulo State, Brazil; (3) Immunogenetics Laboratory, Molecular Biology Department, São José do Rio Preto Medical School, FAMERP, São José do Rio Preto, São Paulo State, Brazil; (4) Biology Department, Institute of Biosciences, Letters and Exact Sciences, São Paulo State University, UNESP, São José do Rio Preto, São Paulo State, Brazil; (5) Specialized Gastroenterology Laboratory, Base Hospital, FUNFARME, São José do Rio Preto, São Paulo State, Brazil.

ABSTRACT: Diseases resulting from Helicobacter pylori infection appear to be dependent on a host of genetic traits and virulence factors possessed by this microorganism. This paper aimed to investigate the association between the $A B O$ histo-blood groups and $H$. pylori cagA infections. Genomic DNA samples $(n=110)$ of gastric biopsies obtained from patients with endoscopic diagnosis of peptic ulcers (n $=25)$ and chronic active gastritis $(n=85)$ were analyzed by PCR using specific primers for the cagA gene. Of the samples, $66.4 \%(n=73)$ tested positive and $33.6 \%$ $(n=37)$ negative for the gene. The cagA strain was predominant in peptic ulcers $(n=$ $21 ; 84.0 \%)$ compared with chronic active gastritis $(n=52 ; 61.2 \%)(p=0.05$; OR 3.332; $95 \% \mathrm{Cl}: 1.050-10.576)$. Additionally, the cagA strain was prevalent in the type O blood (48/63; 76.2\%) compared with other ABO phenotypes $(25 / 47 ; 53.2 \%)(p=$ 0.01 ; OR 2.816; 95\% Cl: 1.246-6.364). These results suggest that $H$. pylori cagA infection is associated with the $O$ blood group in Brazilian patients suffering from chronic active gastritis and peptic ulcers.

KEY WORDS: ABO blood groups, H. pylori infection, cagA strain, chronic active gastritis, peptic ulcers.

FINANCIAL SOURCE: BAP/FAMERP and CAPES.

CONFLICTS OF INTEREST: There is no conflict.

\section{CORRESPONDENCE TO:}

LUIZ CARLOS DE MATTOS, Laboratório de Imunogenética, Departamento de Biologia Molecular, Faculdade de Medicina de São José do Rio Preto, Av. Brigadeiro Faria Lima, 5416, São José do Rio Preto, SP, 15090-000, Brasil. Phone: +55 17 3201 5854. Fax: +55 173229 1777. Email: luiz.carlos@famerp.br or lumattos@msn.com. 


\section{INTRODUCTION}

Infection by Helicobacter pylori is linked to gastroduodenal disease and seems to be dependent on genetic factors of the host and virulence factors presented by this microorganism (1-3).

The involvement of blood group carbohydrates as facilitating factors for infection by this bacillus has previously been reported (4). Some years ago we demonstrated that infection by this Gram-negative bacillus is associated with ABO blood groups in Brazilian patients submitted to upper gastrointestinal endoscopy (5).

Previous reports have shown that $H$. pylori strains that have the cagA gene infect Brazilian patients suffering from various gastroduodenal diseases (6-8). The cagA virulence factor seems to be involved in the induction of proinflammatory chemokines expressed by host cells and plays a notable role in the onset and progression of gastroduodenal diseases $(2,9)$.

$H$. pylori presents a remarkable allelic diversity and genetic variability (3). In addition to readily binding to $A B O$ blood group antigens in the South America Indian population, infective cagA-positive $H$. pylori strains have also been associated with the $A B O$ histo-blood group in Lebanon and Iran (10-12).

Therefore, studies correlating infection by epidemiologically important microorganisms such as $H$. pylori may provide relevant biological and clinical contributions by identifying genetic risk factors of the host and the stages of virulence and pathogenesis of the infectious agent (9). The aim of this study was to investigate the association between the $\mathrm{ABO}$ histo-blood groups and $H$. pylori cagA infection.

\section{MATERIALS AND METHODS}

\section{Type of Study}

This cross-sectional study was carried out in a specialized gastroenterology laboratory at the Base Hospital and the Immunogenetics Laboratory, Molecular Biology Department, São José do Rio Preto Medical School (FAMERP), São José do Rio Preto, São Paulo state, Brazil. After being informed about the experimental nature of this study, written consent was obtained from all patients. The study was approved by the Research Ethics Committee of the institution. 


\section{Patient Selection}

Patients with endoscopy diagnoses of peptic ulcers (PU) or chronic active gastritis (CAG) and $H$. pylori infection were candidates for this study. $H$. pylori infection was identified by routine urea breath and urease tests performed in the specialized gastroenterology laboratory. Additionally, for all cases, whether positive, negative or discordant, the presence of infection was confirmed by PCR using gastric biopsy samples as described in our previous report (5). Patients who were pregnant, aged less than 18 years, had gastrointestinal tract hemorrhages or acute gastritis, had used a proton-pump inhibitor in the previous week or had used an $\mathrm{H}_{2}$ receptor antagonist in the previous 24 hours were excluded from the study. A total of 110 Caucasian and non-Caucasian patients was included in this study.

\section{Blood Sampling and ABO Blood Phenotyping}

Five milliliters of whole blood was drawn from each patient and placed in vacuum tubes with EDTA. The ABO blood group phenotypes were identified by hemagglutination using commercial anti-A, anti-B and anti-A,B sera for forward typing and standard $A_{1}$ and $B$ red blood cells for reverse typing (Fresenius Kabi, Brazil). A drop of a red blood cell suspension in 5\% sterile saline solution $(0.9 \% \mathrm{NaCl})$ prepared for each sample was mixed with a drop of each of the anti-A, anti-B and anti-A,B sera to define the erythrocyte antigens. Two drops of blood plasma from each sample were mixed with one drop of each of the standard $5 \% A_{1}$ and $B$ red blood cell suspensions to identify the anti-A and anti-B antibodies. The tubes were centrifuged at $3400 \mathrm{rpm}$ for 1.5 minutes with the interpretation of the results being based on the presence or absence of hemagglutination. The recommendations of the manufacturer of all reagents were strictly followed.

\section{H. pylori cagA Genotyping}

Genomic DNA samples were extracted from gastric biopsies obtained during endoscopy examinations. The identification of the $H$. pylori strain, based on the detection of the cagA gene, was achieved by PCR according to the previously published protocol (13). PCR reactions were carried out in a final volume of $25 \mu \mathrm{L}$ containing Tris- $\mathrm{HCl} 10$ mM (pH 8.3); $\mathrm{MgCl}_{2} 1.5 \mathrm{mM}$; KCl 50 mM; 5 mM of each dNTP (dATP, dTTP, dCTP, dGTP), $0.5 \mathrm{mM}$ of each primer (forward: 5'GGGCGATCGGTTAGCCCTGA-3'; reverse: 5'-TACCTTACTGAGATC ATCAA-3'); 
$0.5 \cup$ of Taq polymerase and $10 \mathrm{ng}$ of genomic DNA. The amplification conditions were: 35 denaturation cycles at $94^{\circ} \mathrm{C}$ for one minute, annealing at $55^{\circ} \mathrm{C}$ for two minutes and extension at $72^{\circ} \mathrm{C}$ for two minutes. Specific amplified fragments containing 102 base pairs corresponding to the cagA gene were separated by electrophoresis on a $2 \%$ agarose gel in TBE $1 \mathrm{X}$ and visualized using ultraviolet light after ethidium bromide staining.

\section{Statistical Analysis}

The two-tailed Fisher's exact test and odds ratio with a 95\% confidence interval were used to identify associations.

\section{RESULTS}

Of the 110 patients with $H$. pylori infection, 65.4\% ( $\mathrm{n}=72)$ were Caucasians and 43.6\% ( $n=48)$ were non-Caucasians. There was a slight predominance of female ( $n$ $=61 ; 55.4 \%)$ over male $(n=49 ; 44.6 \%)$ patients. Based on endoscopy results, there were three times more patients suffering from CAG $(n=85 ; 77.3 \%)$ than those with PU $(n=25 ; 22.7 \%)$. The O blood group ( $n=63 ; 57.3 \%)$ was prevalent over non-O blood groups (A: $n=33,30.0 \% ; B: n=12,10.9 \% ; A B: n=2,1.8 \%)$.

The rate of $H$. pylori cagA infections was high (66.4\%) but no statistically significant difference was observed when cagA $(+)$ and cagA $(-)$ patients were compared by gender and ethnic background. Table 1 summarizes the results in relation to cagApositive and -negative $H$. pylori strains. 
Table 1. Frequencies of $O$ and non-O blood groups and $H$. pylori infection among 110 patients

\begin{tabular}{|c|c|c|c|c|c|c|c|}
\hline \multirow[t]{2}{*}{ Characteristics } & \multicolumn{2}{|c|}{$\operatorname{cag} A(+)$} & \multicolumn{2}{|c|}{$\operatorname{cag} A(-)$} & \multirow[t]{2}{*}{ OR } & \multirow[t]{2}{*}{$95 \% \mathrm{Cl}$} & \multirow[t]{2}{*}{ P* } \\
\hline & $\mathrm{N}$ & $\%$ & $\mathrm{~N}$ & $\%$ & & & \\
\hline \multicolumn{8}{|l|}{ Gender } \\
\hline Male $(n=49)$ & 33 & 67.3 & 16 & 32.7 & 1.083 & $0.4878-2.403$ & 1.0 \\
\hline Female $(n=61)$ & 40 & 65.6 & 21 & 34.4 & & & \\
\hline \multicolumn{8}{|l|}{ Endoscopy } \\
\hline$P U(n=25)$ & 21 & 84.0 & 4 & 16.0 & 3.332 & $1.050-10.576$ & 0.05 \\
\hline CAG $(n=85)$ & 52 & 61.2 & 33 & 38.8 & & & \\
\hline \multicolumn{8}{|l|}{ ABO blood groups } \\
\hline$O(n=63)$ & 48 & 76.2 & 15 & 23.8 & 2.816 & $1.246-6.364$ & 0.01 \\
\hline Non-O $(n=47)$ & 25 & 53.2 & 22 & 46.8 & & & \\
\hline Total $(n=110)$ & 73 & 66.4 & 37 & 33.6 & & & \\
\hline
\end{tabular}

${ }^{*}$ Calculated by Fisher's exact test

\section{DISCUSSION}

Previous reports that suggesting that infections by the $H$. pylori bacillus may be influenced by genetic traits of the host prompted us to test the hypothesis of an association between the $\mathrm{ABO}$ histo-blood groups and cagA infections.

It is believed that studies on the involvement of this aggressive $H$. pylori strain in the onset and progression of gastroduodenal diseases may provide information central to the development of control and preventive measures against infection (9).

Some years ago we reported an association between the $\mathrm{O}$ blood group and $H$. pylori infections in patients who were submitted to gastric endoscopy with our data being subsequently verified by two studies involving adult and infant patients from different regions of Brazil $(5,14,15)$. Observations that emerged from these studies have been supported by several publications over the last few years $(1-3,9,16)$.

In this paper we demonstrate that in Brazil infection by $H$. pylori carrying the cagA virulence factor is associated with the $\mathrm{O}$ blood group. The rate of infection by this strain reported herein is similar to previous Brazilian studies of adult and infant populations published in recent years (6-8).

The relation between infection by cagA-positive $H$. pylori strains and $A B O$ histo-blood groups has been investigated in different regions. A significant association between this strain and the development of peptic ulcers was observed among Taiwanese patients belonging to the $O$ blood group (17). These authors found that more than 
$85 \%$ of patients suffering from PU and more than $60 \%$ of those with CAG were infected by cagA-positive $H$. pylori strains.

Our study is in agreement with the Taiwanese study which revealed high rates of infection by this strain among patients belonging to the $O$ blood group with $a$ borderline significance level probably due to the small number of patients suffering from PU.

Two recent reports evaluated the association between $A B O$ histo-blood groups and infection by cagA-positive $H$. pylori strains. One of them reported a significant relationship in Lebanon among three factors, namely, infection by this strain, the $A$ blood group and the risk of gastric malignancy (11). The other one demonstrated that the anti-cagA antibody was also slightly more prevalent among infected children with A and $O$ blood groups in Iran (12).

Our results are not concordant with the Lebanese study, but agree, at least in part, with the Iranian study $(11,12)$. It is possible that additional differences in genetic variability of some $H$. pylori strains infecting patients in the Middle East accounted for the differences between these studies. The basis for this association is not totally understood but the ability of $H$. pylori to bind to carbohydrate structures found in receptors, especially those related to histo-blood groups, is attractive (4).

There is no evidence that cagA-positive $H$. pylori strains are able to directly recognize the $\mathrm{H}$ antigen, expressed in the gastrointestinal tract of $\mathrm{O}$ blood group individuals, as a receptor by using the cytotoxin associated antigen A (cagA) as ligand. However, the co-expression of other virulence factors such as blood group adhesin binding A2 (BabA2), which binds to ABO blood group antigens, could explain, at least in part, the association reported in this paper.

$H$. pylori infections by strains carrying the $\operatorname{cag} A$, vacA, ice $A$ and $b a b A 2$ genes were observed among Brazilian adults and children suffering from gastroduodenal diseases $(6-8,18)$. Unfortunately these studies did not analyze the correlation between $\mathrm{ABO}$ blood groups and infection by these strains.

It has been shown that some $H$. pylori strains infecting Amerindians present a certain degree of adaptation that coincides with the high prevalence of the $\mathrm{O}$ blood group among native South Americans. More than 95\% of the BabA-positive $H$. pylori strains are able to bind to $\mathrm{ABO}$ antigens and $60 \%$ of them present a specialized binding pattern to O blood group antigens (10). 
The ABO blood group antigens are carbohydrate structures present in the gastrointestinal tract epithelium while the $\mathrm{H}$ antigen is a fucosylated antigen expressed by the majority of individuals belonging to the $\mathrm{O}$ blood group. This antigen is not modified by glycosyltransferases coded by $A$ or $B$ genes of the ABO locus responsible for the expression of $A$ and $B$ antigens while its level of expression is quantitatively higher than that detected in non-O blood group individuals $(19,20)$. Thus, these quantitative differences may contribute to the high prevalence of $H$. pylori infections among Brazilian patients carrying the babA2 and cagA genes and suffering from CAG and PU.

It is presumed that $H$. pylori co-evolved with its human host but it is not clear whether its introduction into South America was due to waves of native Amerindians migrating across the Central American isthmus or due to colonization by Europeans. The suggestion that ancestral $H$. pylori was present in Peruvian Amerindians prior to the arrival of European colonizers 500 years ago is attractive by virtue of the fact that possible competition between Amerindian and European strains could contribute to the diversification and high genetic variability in the genome of this bacillus in South America (21). Therefore, the consequent acquisition of babA2 and cagA genes would allow the $H$. pylori bacillus to adapt based on the prevalent $A B O$ blood groups in South America (10).

In conclusion, this paper presents evidence of an association between the $\mathrm{O}$ blood group and cagA-positive $H$. pylori infections among Brazilian patients suffering from PU and CAG. This association seems to be an important event which could elucidate the epidemiological basis of the interaction between humans and $H$. pylori.

\section{ACKNOWLEDGEMENTS}

We thank BAP/FAMERP for the research grant (4291/2007) and CAPES for the study grant of F. Nakashima. 


\section{REFERENCES}

1. Nguyen TN, Barkun AN, Fallone CA. Host determinants of Helicobacter pylori infection and its clinical outcome. Helicobacter. 1999;4(3):185-97.

2. Atherton JC. The pathogenesis of Helicobacter pylori-induced gastroduodenal diseases. Annu Rev Pathol. 2006;1:63-96.

3. Suerbaum S, Josenhans C. Helicobacter pylori evolution and phenotypic diversification in a changing host. Nat Rev Microbiol. 2007;5(6):441-52.

4. Borén T, Falk P, Roth KA, Larson G, Normark S. Attachment of Helicobacter pylori to human gastric epithelium mediated by blood group antigens. Science. 1993;262(5141):1892-5.

5. Mattos LC, Cintra JR, Sanches FE, Silva RCMA, Ruiz MA, Moreira HW. ABO, Lewis, secretor and non-secretor phenotypes in patients infected or uninfected by the Helicobacter pylori bacillus. São Paulo Med J. 2002;120(2):55-8.

6. Leite KRM, Darini E, Canavez FC, Carvalho CM, Mitteldorf CATS, Camara-Lopes LH. Helicobacter pylori and cagA gene detected by polymerase chain reaction in gastric biopsies: correlation with histological findings, proliferation and apoptosis. São Paulo Med J. 2005;123(3):113-8.

7. Gatti LL, Fagundes e Souza EK, Leite KR, De Souza Bastos EL, Vicentini LR, Da Silva LC, et al. cagA, vacA alleles and babA2 genotypes of Helicobacter pylori associated with gastric disease in brazilian adult patients. Diagn Microbiol Infect Dis. 2005;51(4):231-5.

8. Gatti LL, Lábio R, Silva LC, Smith MAC, Payão SLM. cagA positive Helicobacter pylori in Brazilian children related to chronic gastritis. Braz J Infect Dis. 2006;10(4):254-8.

9. Kusters JG, van Vliet AHM, Kuipers EJ. Pathogenesis of Helicobacter pylori infection. Clin Microbiol Rev. 2006;19(3):449-90.

10. Aspholm-Hurtig M, Dailide G, Lahmann M, Kalia A, Ilver D, Roche N, et al. Functional adaptation of BabA, the $H$. pylori $\mathrm{ABO}$ blood group antigen binding adhesin. Science. 2004;305(5683):519-22.

11. Sharara AI, Abdul-Baki H, ElHajj I, Kreidieh N, Kfoury Baz EM. Association of gastroduodenal disease phenotype with $\mathrm{ABO}$ blood group and Helicobacter pylori virulence-specific serotypes. Dig Liver Dis. 2006;38(11):829-33. 
12. Jafarzadeh A, Ahmedi-Kahanali J, Bahrami M, Taghipour Z. Seroprevalence of anti-Helicobacter pylori and anti-CagA antibodies among healthy children according to age, sex, $A B O$ blood groups and $\mathrm{Rh}$ status in south-east of Iran. Turk J Gastroenterol. 2007;18(3):165-71.

13. Ito A, Fujioka T, Kodama K, Nishizono A, Nasu M. Virulence-associated genes as markers of strain diversity in Helicobacter pylori infection. J Gastroenterol Hepatol. 1997;12(9-10):666-9.

14. Martins LC, de Oliveira Corvelo TC, Oti HT, do Socorro Pompeu Loiola R, Aguiar DC, dos Santos Barile KA, et al. $\mathrm{ABH}$ and Lewis antigen distributions in blood, saliva and gastric mucosa and $H$. pylori infection in gastric ulcer patients. World $\mathrm{J}$ Gastroenterol. 2006;12(7):1120-4.

15. Rodrigues RV, Corvelo TC, Ferrer MT. Seroprevalence of Helicobacter pylori infection among children of different socioeconomic levels in Porto Velho, State of Rondônia. Rev Soc Bras Med Trop. 2007;40(5):550-4.

16. McNamara D, El-Omar E. Helicobacter pylori infection and the pathogenesis of gastric cancer: a paradigm for host-bacterial interactions. Dig Liver Dis. 2008;40(7):504-9.

17. Lin CW, Chang YS, Wu SC, Cheng KS. Helicobacter pylori in gastric biopsies of Taiwanese patients with gastroduodenal diseases. Jpn J Med Sci Biol. 1998; 51(1):13-23.

18. Mattar R, dos Santos AF, Eisig JN, Rodrigues TN, Silva FM, Lupinacci RM, et al. No correlation of babA2 with vacA and cagA genotypes of Helicobacter pylori and grading of gastritis from peptic ulcer disease patients in Brazil. Helicobacter. 2005;10(6):601-8.

19. Oriol R. ABO, Hh, Lewis and Secretion: serology, genetics and tissue distribution. In: Cartron JP, Rouger P editors. Blood cell biochemistry: molecular basis of human blood group antigens. New York: Plenum; 1995. 37-73 p.

20. Henry SM. Molecular diversity in the biosynthesis of $\mathrm{GI}$ tract glycoconjugates. A blood group related chart of microorganism receptors. Transfus Clin Biol. 2001;8(3):226-30.

21. Devi SM, Ahmed I, Khan AA, Rahman SA, Alvi A, Sechi LA, et al. Genomes of Helicobacter pylori from native Peruvians suggest admixture of ancestral and modern lineages and reveal a western type cag-pathogenicity island. BMC Genomics. 2006;7(1):191. 